\title{
Inclusive Health Conference: Conference-Based Education as an Intervention to Address Medical Education Deficits
}

\author{
Jocelyn Andruko, BHSc${ }^{1}$; Brandon Christensen ${ }^{1}$; Melanie Lewis, MD, FRCPC ${ }^{2}$ \\ ${ }^{1}$ University of Alberta Faculty of Medicine and Dentistry \\ ${ }^{2}$ University of Alberta Faculty of Medicine and Dentistry, Professor of Pediatrics
}

\section{A BSTRACT}

Introduction: Physicians are responsible for the health of all patients, but medical students receive inadequate training on the healthcare needs of LGBTQ (Lesbian, Gay, Bisexual, Transgender, and Queer) patients [1]. Education about cultural issues and proper terminology are also under-addressed. Healthcare practices that cannot demonstrate inclusivity risk alienating patients and perpetuating barriers to patient care for sexual and gender minorities [2].

Methods: In 2013, medical students created the Inclusive Health Conference to address these educational deficits. Experts were invited to present a curriculum including disorders of sexual development, HIV pre-exposure prophylaxis, care for transgender patients, and development of inclusive practices. Self-identified sexual minority patients were also invited to share their experiences. Following these sessions, healthcare professionals and students were asked to complete a survey on knowledge and level of comfort with LGBTQ care.

Results: A majority of respondents stated that they "better understand LGBTQ health issues" (2015 mean 4.39, $\mathrm{n}=41 ; 2016$ mean 4.31, $n=52$ ), "better understand social issues related to LGBTQ healthcare" (2015 mean 4.32, $n=41 ; 2016$ mean 4.31, $n=52$ ) and "feel more comfortable exploring and discussing these issues with LGBTQ people" (2015 mean 4.43, $n=41 ; 2016$ mean 4.17, $n=52$ ).

Conclusions: Based on survey results, this was a successful solution to a critical omission in medical curricula. Of note, the conference also drew attention to this important issue, led to financial sponsorship by the University of Alberta's Faculty of Medicine and Dentistry, initiated curriculum updates, and inspired similar events at other institutions.

\section{RÉ SUM É}

Introduction: Les médecins sont responsables de la santé de tous les patients, mais les étudiants en médecine reçoivent une formation inadéquate en ce qui a trait aux besoins de soins de santé des patients LGBTQ (lesbienne, gai, bisexuel, trans et queer) [1]. Les enjeux culturels et la terminologie appropriée sont également trop peu abordés au cours de la formation. Les pratiques de soins de santé qui ne font pas preuve d'inclusion risquent d'aliéner les patients et de perpétuer les obstacles aux soins de santé pour les personnes de minorités sexuelles et de genre [2].

Méthodes: En 2013, des étudiants en médecine ont créé la conférence Inclusive Health (santé inclusive) afin de combler ce manque éducationnel. Des experts ont été invités à présenter un curriculum qui incluait des désordres de développement sexuel, la prophylaxie préexposition contre le VIH, les soins aux patients transgenres, et l'élaboration de pratiques inclusives. Des patients ayant volontairement déclaré leur appartenance à une minorité sexuelle ont également été invités à partager leurs expériences. À la suite de ces séances, les professionnels de la santé et les étudiants ont rempli un sondage sur leurs connaissances et leur niveau de confort dans la prestation des soins de santé aux personnes LGBTQ.

Résultats: La majorité des personnes interrogées ont affirmé " mieux comprendre les problèmes de santé des personnes LGBTQ » (moyenne de 4,39 en 2015, $n=41$; moyenne de 4,31 en 2016, $n=52$ ), " mieux comprendre les enjeux sociaux liés à la prestation des soins de santé aux personnes LGBTQ » (moyenne de 4,32 en 2015, $n=41$; moyenne de 4,31 en 2016, $n=52$ ) et « se sentir plus à l'aise d'explorer et de discuter de ces problèmes avec les personnes LGBTQ ॥ (moyenne de 4,43 en 2015, n= 41; moyenne de 4,17 en 2016, $\mathrm{n}=52$ ).

Conclusions: En se fondant sur les résultats du sondage, la conférence s'est avérée efficace pour contrer une omission importante dans les curriculums médicaux. En outre, la conférence a attiré l'attention sur cet important problème, a mené à un parrainage par la Faculté de médecine et de médecine dentaire de l'Université d’Alberta, a entraîné des mises à jour aux curriculums médicaux, et a inspiré des évènements semblables à d'autres établissements.

Keywords: LGBTQ; Lesbian; Gay; Bisexual; Transgender; Queer; HIV; Medicine; Global Health; Pediatrics; Inclusive Health; Community Engagement 


\section{INTRODUCTION}

\author{
Healthcare Deficits
}

LGBTQ (Lesbian, Gay, Bisexual, Transgender, and Queer) individuals have additional and unique healthcare needs including higher rates of mental health issues, substance use, and sexually transmitted infections. LGBTQ youth also have higher rates of teen pregnancy [3].

Literature also demonstrates that LGBTQ populations are not receiving the healthcare they need to address those health concerns. Canadian LGBTQ people have been shown to be less likely to have a regular healthcare provider, and lesbian women in particular are less likely to have seen a family doctor or have cervical cancer screening within the past 12 months [4]. Even compared against other sexual and gender minorities, transgender patients have particular difficulty accessing good quality healthcare. In a recent study, amongst transgender persons, $21 \%$ admitted to avoiding emergency room (ER) care and 52\% reported facing trans-negative ER experiences [5]. It has also been identified that $25 \%$ of transgender Ontarians obtain hormones from nonmedical sources, $6.4 \%$ take non-prescribed hormones, and $2.3 \%$ have performed or attempted surgical procedures on themselves in an attempt to self-treat [6]. This is undoubtedly a population underserved by our current medical system.

\section{Barriers to Healthcare}

A number of studies have attempted to identify the etiology of this longstanding problem, which is likely complex and multifactorial. Particular moments of distrust or discomfort that LGBTQ patients experience with medical care include coming out to providers, fear of being denied safe care, providers' insistence about unnecessary pregnancy tests or contraception, and misidentification or mixing-up of preferred pronouns [2]. Physician self-reported discomfort was also significant, and mainly related to feeling underprepared or unable to provide adequate care [2].

\section{Existing Educational Context}

This physician discomfort is unsurprising in the context of existing medical education surrounding these issues. North American medical schools average 2 hours of dedicated LGBTQ content across all four years of medical school; 44 schools report zero dedicated hours during clinical years and 9 schools report zero dedicated hours over all four years. When surveyed, a majority of deans of medical education were dissatisfied with their institutions' coverage of LGBTQ-related topics [1]. If provided with proper education, it is reasonable to expect that physicians may be more comfortable caring for LGBTQ individuals, which may in turn reduce patient discomfort with accessing care and improve healthcare outcomes overall.

\section{Educational Intervention}

In response to a lack of a focused LGBTQ curriculum at their institution, the Sexual Orientation and Gender Identity Advocacy (SGA) committee, composed of medical students at the University of Alberta, developed an educational platform to share best practices in LGBTQ health. This initiative, starting in 2014, was an annual, one-day student-led conference to educate medical students, residents, physicians, and other healthcare professionals in social and medical issues related to sexual and gender minorities.

\section{Study Objectives}

As part of the ongoing evaluation of this conference, a survey was conducted among healthcare professional and student attendees in 2015 and 2016. The objective was to assess the efficacy of this student-led conference as a short-term educational intervention to improve knowledge and comfort with a specific set of topics. The primary outcome for this survey was self-assessed improvement in knowledge and comfort. It was hypothesized that attendees would report at least moderate improvement in knowledge and comfort with these topics after receiving formal teaching on this curriculum. Secondary outcomes included subjective written comments.

\section{METHODS}

\section{Curriculum Development and Content}

As existing curricula on these topics were not readily available at the time, curriculum objectives were developed using a community engagement model; individuals and experts in the community were consulted each year, approximately 8 months in advance, to collect a list of possible relevant topics and themes. Once an appropriate list of topics was agreed upon, the organizers worked within the community to develop a network of experts to present. Where possible, local individuals were chosen to provide an accurate context of the local LGBTQ community. Experts included MDs, PhDs, and specialists in education policy research.

In the development of this curriculum, there was a particular focus on including a balance of relevant topics, including HIV treatment and pre-exposure prophylaxis, disorders of sexual development, psychiatric and endocrinologic assessment of transgender individuals, and family planning for same-sex couples. Speakers and panels of LGBTQ community members sharing personal experiences were also included, to provide a perspective of lived experiences and challenges for this population. 
A unique overall theme was also selected each year through the same community engagement model, to reflect current events and issues. In 2015, the focus was care for transgender patients, including a curriculum on hormone therapy for transgender teens. In 2016, the overall theme was care for at-risk populations of gay men, including new research about HIV pre-exposure prophylaxis and speakers with personal stories reflecting the intersectionality of LGBTQ individuals with other at-risk populations, including First Nations, homeless, addicted, and HIV-positive individuals. These yearly themes allowed the curricula to provide a greater focus on relevant and current information, while still allowing for a breadth of overall content.

Each conference included approximately 8 hours of curricular time, including didactic lectures (60\%), interactive panels and discussions (20\%), and small-group breakout sessions (20\%) to maximize audience engagement. The 2016 conference was accredited to provide Continuing Medical Education (CME) accreditation for family physicians in attendance, to further motivate interested physicians to attend.

\section{Survey Development}

An optional survey (Text Box 1) was developed with the help of Dr. Kris Wells, an Assistant Professor at the University of Alberta's Faculty of Education, and a well-known expert in this field. The survey collected demographic information including gender, sexual orientation, and profession, as well as a score (out of 5) for agreement to each of the statements provided. Each question included the option "prefer not to answer" and identifying information was not collected. A space for subjective comments was included.

In the context of this survey, the previously stated hypothesis (that a moderate improvement in knowledge and comfort would be reported) was interpreted as a mean score of 4 for each question.
Inclusion and Exclusion Criteria

Inclusion criteria were that participants have self-identified as a physician, medical student, resident, or other healthcare professional. Exclusion criteria included those who were not able to attend at least one half-day of the Inclusive Health Conference in any of its most recent two yearly events. All conference attendees were evaluated for these criteria by student volunteers at registration. If criteria were met, the attendee was offered a paper survey by the study team, with verbal and written instructions and study information. Consent to participate was defined as returning a completed survey to the submission drop box provided.

Because no identifying information was collected, no data were excluded once surveys had been collected. There were no invalid entries that had to be excluded. Because all questions were made optional to protect confidentiality, some respondents did not complete every question, which is reflected by a slightly different total $\mathrm{n}$ in some results.

Both survey and study methods were reviewed and approved by the Research Ethics and Management board at the University of Alberta.

\section{RESULTS}

\section{Study Population}

An analysis of demographic information revealed that this group of attendees were different from the general population in several ways, including a greater proportion of women and of sexual minorities (Table 1). Despite targeting curriculum development and advertising towards physicians, residents, and students, the greatest proportion of attendees were nurses, medical students, and nursing students (Table 2).

Text Box 1: Example Survey

Please rate your agreement with the following statements:

1 = strongly disagree, 2 = disagree, $3=$ neutral, 4 = agree, 5 = strongly agree

After attending this conference,

I better understand LGBTQ health issues. 1 / 2 / 3 / 4 / 5

I better understand social issues related to LGBTQ healthcare. 1 / 2 / 3 / 4 / 5

I feel more comfortable exploring and discussing these issues with LGBTQ people. 1 / 2 / 3 / 4 / 5

I feel more comfortable working with LGBTQ patients. 1 / 2 /3 / 4 / 5

I feel compelled to learn more about these topics. $1 / 2 / 3 / 4 / 5$

I know where I can find more information about these topics. 1 / 2 /3 / 4 / 5 


\section{Primary Outcome}

Overall mean scores for each statement were found to be positive, all above 4.00 (Table 3). Highest scores were reported for the statement, "I feel compelled to learn more about these topics," which reflects an understanding of the importance of these educational topics.

\section{Secondary Outcome}

A subgroup analysis was performed for mean scores between demographic groups (Tables 4 and 5). Surprisingly, mean scores were notably higher for female attendees compared to male attendees. However, there was no significant difference in reported scores between individuals of different sexual orientations.

\section{Subjective Comments}

Two reviewers independently read these comments, and agreed upon overall themes. Positive comments reflected particular appreciation for panel discussions and personal stories, as well as for sessions on treatment for transgender patients (assessing readiness for transition, teaching on hormonal therapy, and indications for referral to specialists). Negative comments mainly suggested to focus less on the yearly theme (men who have sex with men, or transgender health) and to provide printed presentation slides.

\section{DISCUSSION}

\section{Study Merits and Limitations}

The degree to which these positive results can be interpreted is limited by a number of factors, the most obvious being the nature of self-assessment as an effective evaluation tool. Selfassessed measures of confidence or competence are poor surro- gates for measuring actual achievement, and might show a large improvement where minimal change has taken place.

The validity of these results may also be limited by selection bias: as it was impossible to randomize participants and to protect confidentiality, this study did not record participants who accepted surveys but did not submit responses. As a result, the demographics measured on this survey may differ from the overall population of healthcare professionals. Those who attended potentially have personal interest in issues presented, and therefore may be motivated to overstate a positive response. On the other hand, this population may also be more likely to be involved with the LGBTQ community to start with, so may already understand objectives presented and learn nothing new. Given these opposing factors, it is difficult to know whether the data might be skewed more positive or negative. With future evaluation studies, our research team hopes to minimize these biases.

Despite these limitations, given such positive survey feedback, it may still be reasonable to suggest that this educational initiative has been effective, especially given the context of limited or entirely absent formal curricula on these topics.

In this context, it is also important to consider secondary outcomes, which included both subjective comments and a subgroup analysis. It is difficult to explain the meaning of the difference between self-reported scores for male and female respondents; the study team hopes to elicit whether and how this finding is significant on future studies. It is interesting to note that there was no significant difference between responses from heterosexual, homosexual, and bisexual groups; this may suggest that the information presented is not widely understood among LGBTQ communities, even those with enough interest in healthcare to attend such a conference, and further highlights the need for expertise among healthcare professionals. Despite targeting both curriculum development and advertising efforts at medical

Table 1: Demographics by gender and sexual orientation.

\begin{tabular}{|l|c|c|c|}
\hline \multicolumn{3}{|c|}{2015} & 2016 \\
\hline Gender & $12(29.3 \%)$ & $15(30.0 \%)$ & $27(29.7 \%)$ \\
\hline Memale & $29(70.7 \%)$ & $35(70.0 \%)$ & $64(70.3 \%)$ \\
\hline Sexual Orientation & & $27(55.1 \%)$ & $49(55.1 \%)$ \\
\hline Heterosexual & $22(55.0 \%)$ & $13(26.5 \%)$ & $22(24.7 \%)$ \\
\hline Homosexual & $9(22.5 \%)$ & $7(14.3 \%)$ & $10(11.2 \%)$ \\
\hline Bisexual & $3(7.5 \%)$ & $2(4.1 \%)$ & $8(9.0 \%)$ \\
\hline Other & $6(15.0 \%)$ & \\
\hline
\end{tabular}


Table 2: Demographics by health profession.

\begin{tabular}{|c|c|c|c|}
\hline Health Profession & 2015 & 2016 & Total \\
\hline Nurse & 14 & 22 & 36 \\
\hline Nurse Practitioner & 0 & 1 & 1 \\
\hline Physician & 2 & 2 & 4 \\
\hline Psychologist & 1 & 2 & 3 \\
\hline Pharmacist & 0 & 1 & 1 \\
\hline Pharmacy Technician & 0 & 1 & 1 \\
\hline Occupational/Physical Therapist & 2 & 1 & 3 \\
\hline Social Worker & 1 & 0 & 1 \\
\hline Health Education & 3 & 2 & 5 \\
\hline Nursing Student & 6 & 5 & 11 \\
\hline Medicine Student & 10 & 10 & 20 \\
\hline Pharmacy Student & 2 & 1 & 3 \\
\hline Medical Lab Science Student & 0 & 1 & 1 \\
\hline Psychology Student & 0 & 1 & 1 \\
\hline $\begin{array}{l}\text { Occupational/Physical Therapy } \\
\text { Student }\end{array}$ & 0 & 1 & 1 \\
\hline Total & 41 & 51 & 92 \\
\hline
\end{tabular}

Table 3: Mean scores by survey statement.

\begin{tabular}{|c|c|c|c|c|}
\hline Statement & \multicolumn{2}{|r|}{2015} & \multicolumn{2}{|r|}{2016} \\
\hline & Mean & Standard Deviation & Mean & Standard Deviation \\
\hline I better understand LGBTQ health issues & 4.39 & 0.703 & 4.31 & 0.612 \\
\hline $\begin{array}{l}\text { I better understand social issues related to LGBTQ } \\
\text { healthcare }\end{array}$ & 4.32 & 0.650 & 4.31 & 0.673 \\
\hline $\begin{array}{l}\text { I feel more comfortable exploring and discussing these } \\
\text { issues with LGBTQ people }\end{array}$ & 4.43 & 0.712 & 4.17 & 0.793 \\
\hline I feel more comfortable working with LGBTQ patients & 4.44 & 0.594 & 4.17 & 0.760 \\
\hline I feel compelled to learn more about these topics & 4.66 & 0.530 & 4.54 & 0.727 \\
\hline $\begin{array}{l}\text { I know where I can find more information about these } \\
\text { topics }\end{array}$ & 4.28 & 0.909 & 4.25 & 0.789 \\
\hline
\end{tabular}


Table 4: Subgroup analysis by sexual orientation.

\begin{tabular}{|c|c|c|c|c|c|c|}
\hline \multirow[t]{2}{*}{ Statement } & \multicolumn{3}{|c|}{2015} & \multicolumn{3}{|c|}{2016} \\
\hline & $\begin{array}{c}\text { Mean } \\
\text { (Hetero-sexual) } \\
n=22\end{array}$ & $\begin{array}{c}\text { Mean } \\
\text { (Homo-sexual) } \\
n=9\end{array}$ & $\begin{array}{c}\text { Mean } \\
\text { (Bi-sexual) } \\
n=3\end{array}$ & $\begin{array}{c}\text { Mean } \\
\text { (Hetero-sexual) } \\
n=27\end{array}$ & $\begin{array}{c}\text { Mean } \\
\text { (Homo-sexual) } \\
n=13\end{array}$ & $\begin{array}{c}\text { Mean } \\
\text { (Bi-sexual) } \\
n=7\end{array}$ \\
\hline $\begin{array}{l}\text { I better understand LGBTQ } \\
\text { health issues }\end{array}$ & 4.41 & 4.30 & 4.67 & 4.33 & 4.14 & 4.57 \\
\hline $\begin{array}{l}\text { I better understand social } \\
\text { issues related to LGBTQ } \\
\text { healthcare }\end{array}$ & 4.41 & 4.30 & 4.33 & 4.37 & 4.15 & 4.57 \\
\hline $\begin{array}{l}\text { I feel more comfortable ex- } \\
\text { ploring and discussing these } \\
\text { issues with LGBTQ people }\end{array}$ & 4.32 & 4.60 & 4.67 & 4.22 & 4.08 & 4.00 \\
\hline $\begin{array}{l}\text { I feel more comfortable } \\
\text { working with LGBTQ patients }\end{array}$ & 4.45 & 4.60 & 4.33 & 4.26 & 4.00 & 4.29 \\
\hline $\begin{array}{l}\text { I feel compelled to learn } \\
\text { more about these topics }\end{array}$ & 4.64 & 4.80 & 5.00 & 4.52 & 4.54 & 4.86 \\
\hline $\begin{array}{l}\text { I know where I can find more } \\
\text { information }\end{array}$ & 4.36 & 4.20 & 4.00 & 4.15 & 4.00 & 4.86 \\
\hline
\end{tabular}

Table 5: Subgroup analysis by gender.

\begin{tabular}{|c|c|c|c|c|}
\hline \multirow[t]{2}{*}{ Statement } & \multicolumn{2}{|c|}{2015} & \multicolumn{2}{|c|}{2016} \\
\hline & $\begin{array}{l}\text { Mean (Male) } \\
n=12\end{array}$ & $\begin{array}{l}\text { Mean (Female) } \\
\qquad n=29\end{array}$ & $\begin{array}{l}\text { Mean (Male) } \\
\quad \mathrm{n}=15\end{array}$ & $\begin{array}{l}\text { Mean (Female) } \\
\mathrm{n}=35\end{array}$ \\
\hline I better understand LGBTQ health issues & 4.08 & 4.52 & 3.93 & 4.46 \\
\hline $\begin{array}{l}\text { I better understand social issues related to LGBTQ health- } \\
\text { care }\end{array}$ & 4.17 & 4.38 & 4.00 & 4.46 \\
\hline $\begin{array}{l}\text { I feel more comfortable exploring and discussing these is- } \\
\text { sues with LGBTQ people }\end{array}$ & 4.33 & 4.46 & 3.80 & 4.31 \\
\hline I feel more comfortable working with LGBTQ patients & 4.25 & 4.52 & 3.73 & 4.40 \\
\hline I feel compelled to learn more about these topics & 4.42 & 4.76 & 4.47 & 4.63 \\
\hline $\begin{array}{l}\text { I know where I can find more information about these } \\
\text { topics }\end{array}$ & 3.79 & 4.48 & 3.62 & 4.49 \\
\hline
\end{tabular}


students, residents, and physicians, and having a planning committee almost entirely of medical students, there was a wide variety of healthcare professions represented among attendees at this conference. This may reflect not only the greater number of non-physician healthcare professionals in our area, but the relevance of these topics for any healthcare professional.

Subjective comments suggested that topics related to care for transgender patients and personal stories about patient experiences were the most helpful and well received by attendees. They also suggested that printed educational materials and a more general focus with less focus on the yearly theme may further improve this program. Organization of the Inclusive Health Conference in 2017 and future years will continue to improve based on this feedback.

\section{Other Results}

There were a number of other results not directly studied, but with strong implications in understanding the value of this conference as an educational initiative. The most notable of these was the faculty attention directly generated by this conference's success. Following the first event in 2014, organizers and leaders were invited to a curriculum development committee, to write learning objectives to solve the educational deficit they had attempted to address. Although there remains much work to be done, this strongly suggests that independent educational initiatives may impact long-term formal curriculum changes. After the success of the initial conference in 2014, the Faculty of Medicine and Dentistry also provided a $\$ 100,000$ grant for continuing yearly events, which further demonstrates their attention and support. Student colleagues at the University of Calgary have also since developed an analogous event at their own school, which highlights the possibility of nation-wide spread for important curriculum updates.

The media and community attention generated by this conference is also notable: over the last two years of this conference, organizers were invited onto three different local news networks, have been interviewed for a number of local and online newspapers, and have received several prestigious awards from the University of Alberta and its associated residency programs. This demonstrates the ability of such events to generate awareness and concern in the greater academic and local community, which can further address social and educational issues in ways that are much more difficult to measure.

\section{CONCLUSION}

An anonymous survey was used to evaluate this educational initiative. These results were very positive; despite unavoidable biases, this reflects both a lack of formal education on these top- ics and the ability of a short-term educational conference to address that deficit. We hope this work may serve as inspiration for similar initiatives in other schools, as well as for more formal medical curriculum development. More work must be done in the development of this initiative, including targeting curricula at a wider group of healthcare professionals and curriculum evaluation using more objective measures of knowledge and improvement. Ultimately, we hope to provide a more comprehensive curriculum which can be used to develop more formal changes at medical schools across the country.

\section{ACKNOWLEDGEMENTS}

The authors would like to thank Dr. Kris Wells, Assistant Professor at the Faculty of Education at the University of Alberta, for his help generating the survey, as well as the University of Alberta's Faculty of Medicine and Dentistry for their generosity in funding the Inclusive Health Conference.

\section{CONFLICTS OF INTEREST}

The authors have no conflicts of interest to disclose. The University of Alberta's Faculty of Medicine and Dentistry provided funding for the conference initiative described, but did not financially support the associated research study.

\section{REFERENCES}

1. Obedin-Maliver J, Goldsmith ES, Stewart L, et al. Lesbian, gay, bisexual, and transgender-related content in undergraduate medical education. JAMA. 2011;306(9):971-7.

2. Harbin A, Beagan B, Goldberg L. Discomfort, judgment, and health care for queers. J Bioeth Inq. 2012;9(2):149-60.

3. Saewyc EM, Poon CS, Homma Y, Skay CL. Stigma management? The links between enacted stigma and teen pregnancy trends among gay, lesbian, and bisexual students in British Columbia. Can J Hum Sex. 2008;17(3):123-39.

4. Tjepkema M. Health care use among gay, lesbian and bisexual Canadians. Component of Statistics Canada, Catalogue no. 82-003-X Health Reports. 2008;19(1):53-64.

5. Bauer GR, Scheim Al, Deutsch MB, Massarella C. Reported emergency department avoidance, use, and experiences of transgender persons in Ontario, Canada: results from a respondent-driven sampling survey. Ann Emerg Med. 2014;63(6):713-20.e1.

6. Rotondi NK, Bauer GR, Scanlon K, Kaay M, Travers R, Travers A. Nonprescribed hormone use and self-performed surgeries: "do-it-yourself" transitions in transgender communities in Ontario, Canada. Am J Public Health. 2013;103(10):1830-6. 